

\section{Reflexões sobre ensino (ou sobre mediação?) da literatura}

RESUMO: Este texto levanta reflexões sobre o mediação escolar nos processos de escolarização da leitura literária. Comenta inicialmente a produção de leitura de três textos de gêneros diferenciados, realizada por professores em processo de formação, revelando uma pluralidade das possibilidades de leitu-

Aracy Alves Martins Doutor em Educação Professora Adjunta da Faculdade de Educação da UFMG aracy.martins@terra.com.br ra na relação autoria/textos/leitores. Estabelece uma diferenciação entre ensino e mediação, principalmente no campo das manifestações culturais, na direção da literatura, enquanto produção artística. Aponta a necessidade de se engendrarem projetos de formação cultural de professores, em prol da formação de leitores e da democratização da leitura.

PALAVRAS-CHAVE: escolarização, mediação, leitura literária, formação cultural

\begin{abstract}
VII
No descomeço era o verbo. Só depois é que veio o delírio do verbo. O delírio do verbo estava no começo, lá onde a a criança: Eu escuto a cor dos passarinhos. A criança não sabe que o verbo escutar não funciona para cor, mas para som. Então se a criança muda a função de um verbo, ele delira. E pois. Em poesia que é voz de poeta, que é a voz de fazer nascimentos O verbo tem que pegar delírio.
\end{abstract} VIII

Um girassol se apropriou de Deus: foi em Van Gogh. Manoel de Barros (2000, p. 15) 
(1) Cf. in Soares, 1988, citando Orlandi, (ORLANDI, Eni. A linguagem e seu funcionamento. São Paulo: Brasiliense, 1983), a noção de que "a leitura é produzida" diferentemente, a partir da interação que leitores diversos estabelecem com o texto. Segundo Soares, talvez "não se possa falar de ideologia subjacente ao texto, mas de ideologias subjacentes às leituras que de um mesmo texto são feitas" (p.27).

\section{Introdução}

A intenção deste trabalho é estabelecer uma interlocução com professores que tomam para si a tarefa de trabalhar na escola, abrangendo uma diversidade de gêneros textuais, a leitura literária, a fim de levantarmos juntos algumas reflexões que nos possam ser úteis na construção de uma "didática da invenção", como diria o autor da epígrafe acima, no processo de formação de leitores.

Com esse objetivo, buscamos descobrir, com uma turma de pós-graduandos do curso de Especialização, elementos para uma reflexão sobre ensino da literatura, realizando uma atividade coletiva de produção de leitura ${ }^{1}$.

\section{Uma produção de leitura}

O primeiro texto - Um conto Sufi - é um filme de curta metragem, com duração de oito minutos, em cores, de Gayle Thomas, produzido no Canadá por Derek Lamb, baseado em uma fábula persa, constituído de sons expressivos e de imagens que se transformam em outras, compondo uma narrativa, cujo texto fica por conta dos espectadores.

O segundo - O Cego Estrangeiro - também é um filme de curta metragem, com oito minutos, dirigido por Marcius Barbieri. A voz do narrador é de Luís Orione Lula, que também fez a tradução. Nesse filme o espectador lida apenas com a música, com as entonações expressivas do narrador, com os sons de ambientação da cena e com a legenda. Por uma questão de adequação do suporte às condições de produção, e sendo o produtor do texto um narrador cego, o filme, portanto, não tem nenhuma imagem.

O terceiro texto é um poema que se encontra na página do meio do livro classificado como literatura infanto-juvenil, $O$ fazedor de amanhecer, de Manoel de Barros (2001), competentemente ilustrado por Ziraldo: um menino, atônito, mas atento, se sente dividido entre dois pássaros. Do lado do pássaro brasileiro, a camisa do menino é de listras verdes, amarelas e brancas; do lado do oiseau, as listras são vermelhas, azuis e brancas. 
Não sinto o mesmo gosto nas palavras:

Oiseau e pássaro.

Embora elas tenham o mesmo sentido.

Será pelo gosto que vem de mãe? de língua mãe?

Seria porque eu não tenha amor pela língua

de Flaubert?

Mas eu tenho.

(Faço este registro

porque tenho a estupefação

de não sentir com a mesma riqueza as

\section{A LIINGUA MÃE}

palavras oiseau e pássaro)

Penso que seja porque a palavra pássaro

em mim repercute a infância

E oiseau não repercute.

Penso que a palavra pássaro carrega até hoje Nela o menino que ia de tarde pra debaixo das árvores a ouvir os pássaros.

Nas folhas daquelas árvores não tinha oiseaux Só tinha pássaros.

É o que me ocorre sobre língua mãe.

Na produção de leitura do texto O Conto Sufi, o grupo de pós-graduandos construiu como sentido as diferentes reações dos membros de uma comunidade, mediante o surgimento de um elemento novo, desconhecido. O que provoca essas diferentes reações é a natureza da interação estabelecida entre dois tipos de sujeito que conheciam esse elemento novo e a comunidade. $\mathrm{O}$ primeiro sujeito se posiciona como o detentor do saber, que vai passar o seu conhecimento para os demais, não conseguindo, no entanto, vencer o receio dos membros da comunidade em relação ao elemento novo; por isso é sumariamente expulso por eles. O segundo convida os membros da comunidade a experimentar, a sentir o sabor do tal elemento, já que se trata de um fruto. Esse processo de degustação vai contagiando mais e mais pessoas, que, tendo descoberto, junto ao segundo sujeito, a possibilidade de plantar a semente, passa a produzir aquele fruto em larga escala.

Quanto ao segundo texto, os pós-graduandos espectadores foram, a cada passo, a partir da legenda, cumprindo o propósito da obra: "a idéia desse filme é que o espectador reconstruísse a história em sua cabeça, a partir da leitura da legenda, assim como acontece quando se lê um livro"². E que recurso foi utilizado pela autoria $^{3}$ para que essa leitura da legenda se processasse? O texto é oralizado pelo narrador cego, numa linguagem que é, na verdade, uma composição com palavras de vários idiomas: francês, português, italiano, espanhol, inglês etc. A legenda precisa ser

(2) Programa Curta Minas - Rede Minas de Televisão - 0l.07.01, 17h. www.redeminas.com.br.

(3) O uso do termo autoria aqui se justifica porque cada texto não tem apenas um autor, mas uma equipe de autoria. No caso de filmes, por exemplo, há os profissionais que 
produzem o roteiro, a música, a fotografia, a montagem, a edição de som, a direção, etc. No caso de livros, há os profissionais que produzem o texto escrito, a ilustração, o projeto gráfico, a diagramação, a edição, etc. Todos esses elementos constituem o texto como um todo na relação autores/espectadores, autores/leitores.

(4) Ver anexo.

(5) 5 JOZEF, Bella. $\boldsymbol{A}$ máscara e o enigma. Rio de Janeiro: Francisco Alves, 1986. escrita na língua falada pelos espectadores para que eles consigam imprimir sentido à narrativa, uma história de amor, numa atividade de leitura, que vai deflagrar um exercício de imaginação ${ }^{4}$. Este vai depender tanto do conhecimento enciclopédico (Eco, 1986) quanto do repertório de leituras e de histórias de cada um.

A leitura do poema "A língua mãe" levou os pós-graduandos a elaborarem a idéia de que a atribuição de sentidos de um texto vai depender também, e acima de tudo, das percepções, que são legados da cultura, dos gostos e estilos de vida de cada leitor (Bourdieu, 1983).

Enfim, constatamos juntos que esses textos trazem em comum a exploração da possibilidade de participação efetiva de interlocutores diferenciados, carregando, ao produzir a sua leitura, cada leitor a sua cultura. Leva-se, então, em consideração que o texto é uma "construção ativa", em que cada leitura é uma nova escrita de um texto. O ato da criação não estaria, assim, na escrita mas na leitura, o verdadeiro produdor não seria o autor mas o leitor (Bella Jozef ${ }^{5}$, apud Soares, 1988).

E ainda podemos pensar, como pensamos sobre a autoria, leitor no plural. Vem de Gumbrecht (1998) a noção de diferentes disposições receptivas mediante as convergências do texto. Essas convergências se constituem de vazios deliberados, deixados pela autoria, a fim de que cada leitor possa preenchê-los a partir da sua própria experiência de vida. Fala-se aqui, então, de recepções diferenciadas de leitores plurais, porque diversos em sua história.

Todas essas obras foram construídas pelos autores com a esperteza de deixar, através de determinadas palavras, estruturas, diagramações, imagens, não-imagens, movimentos, silêncios ou sons, alguma faceta constitutiva da obra para ser elaborada pelos leitores, já que somente assim se complementará a criação. São indícios meticulosamente construídos pela autoria, a fim de que os leitores, a partir deles, consigam pegar delírio.

E em que sentido seria esse delírio? O próprio dicionário Aurélio atribui um certo sentido ao verbo delirar: 3. Sentir e/ou manifestar com excesso ou com grande intensidade: delirar de ódio; delirar de prazer. A partir de que outros sentimentos podemos delirar? Não seria a partir de quaisquer dos sentimentos humanos? Amor? Saudade? Desespero? Revolta? Indignação? Não se trata, 
portanto, de fazer exercícios de imaginação para uma fuga da realidade, mas, muitas vezes, para uma tomada de consciência sobre a contraditória e angustiante condição humana ${ }^{6}$.

Se assim é, ponderamos sobre como poderia ser o trabalho com a produção da leitura literária na escola. Por que insistir em trabalhar por uma perspectiva estritamente objetiva uma atividade tão subjetiva para cada leitor e sua cultura? Não seria possível aos professores partilharem leituras, num exercício de mediação cultural?

\section{Sobre mediação cultural}

Caillet (1995), considerando a mediação no museu como uma passagem, mostra a representação que, geralmente, se tem da escola e dos professores, citando Denis Guedj ${ }^{7}$, autor que define o mediador como um passante.

Um passante que, precisamente, não é um professor no sentido usual do termo: eu quero sublinhar a diferença que separa mediação de ensino. Parece-me de fato fundamental ver que os museus não se tornaram lugares de ensino, mas permaneceram lugares onde não há obrigação: não se tem que compreender qualquer coisa. Os museus são lugares de cultura. O que não quer dizer que não haja ali saber. Os lugares de ensino são lugares de obrigação, o que faz com que se passe primeiro o ensinamento e não o saber. A noção de mediação repousa sobre essa distinção essencial: Eu te faço saber, diz o mediador; eu te ensino, diz o professor.

Certamente está embutida nessa fala uma idéia preconcebida e alardeada do que seja o professor: um transmissor de conhecimentos a serem impostos. Além de fazer essa diferenciação, Guedj distingue, de outro modo, as condições oferecidas pelo museu e as oferecidas pela escola: há uma estranha liberdade no museu: nada de programa, nada de coerção; não há exaustividade em momento de cultura. Infelizmente, porém, haveremos de convir que haja aí algumas constatações latentes, que fazem tais preconceitos se transformarem em insinuações pertinentes, no que diz respeito à produção de conhecimentos na escola. Certamente ainda não temos constituído suficientemente a escola como um lugar de cultura (Cf. Evangelista, 2000).

O que fazem (ou não fazem) a escola e os sistemas de ensino, para deixar que se construam representações de professores ape-
(6) Nesse mesmo encontro com os pós-graduandos, fizemos uma leitura crítica da escolha de textos realizada por uma estagiária de Prática de Ensino de Português - Letícia Mendes de Oliveira, do Curso de Letras - para o seu projeto de estágio, cujo tema era "Leitura e interpretação sobre a questão dos catadores de papel e a exclusão social". Além dos textos informativos e jornalísticos sobre o tema, figuram, em primeiro lugar, os poemas Luxo, de Augusto de Campos (Poesia. S.P: Brasiliense, 1986), e O Bicho, de Manuel Bandeira (Estrela da vida inteira, Rio, 1966).

(7) GUEDJ, Denis. Lettre des musées de France. Paris : D.M. F., 1991. 
nas como transmissores e impositores do saber? Além disso, a escola não é também um lugar de cultura? Os lugares do ensino são somente de obrigação? Como fazer, no domínio da literatura, para ensinar e fazer saber? Como trabalhar na escola, com uma necessária liberdade, para evitar a exaustividade?

\section{Sobre mediação da leitura literária}

Considerando a literatura, ao mesmo tempo, uma produção lingüística e uma produção cultural, estamos assumindo, para o desenvolvimento das atividades de leitura literária na escola, uma concepção mais de mediação do que de ensino, a exemplo de outras manifestações culturais, como a música, a pintura, a escultura; enfim, as artes em geral.

No ensino fundamental, o intuito seria mediar a relação dos alunos com um tipo de manifestação cultural que também acontece na escola: a literatura. Seria estarem os professores entre os seus alunos-leitores e as obras literárias, conhecendo uns e outras - os interesses (variados) dos alunos e a potencialidade (múltipla) das obras -, para promoverem esse encontro, ressaltando a importância das predisposições iniciais dos próprios leitores, como ponto de partida para o alargamento do seu universo de leituras, a fim de, como diria Lopez (1996), no campo da música, acostumar esse público, lentamente e com confiança, a entrar nesse universo literário, numa aproximação natural. Esse autor defende que bem melhor do que sugestões paternalísticas é o interessado procurar por si mesmo, sendo muito importante a predisposição aquilo que não é imposto, exceto por imperativos do íntimo. A busca de conhecimentos na área se daria na medida da necessidade de esclarecimentos que facilitassem a aproximação e a mediação.

O que seria necessário os professores saberem, para melhor mediarem as situações de leitura literária, postas a serviço dos jovens leitores? Bastariam aos professores os conhecimentos sobre leitura e sobre literatura?

Sobre uma costumeira assimetria entre as experiências de leitura da clientela escolar e as expectativas de leitura da instituição escolar, Lajolo afirma que será uma violência se na sua prática a escola desconsiderar as experiências prévias e imagens de leitura e de literatura que sua clientela alimenta (1995, p. 119).

Nesse sentido, o grande temor dos professores, quando se 
defende a importância de partir das experiências prévias, é que se confinem os alunos a seu próprio habitus e que os alunos de camadas populares não desenvolvam estratégias, nem conhecimentos e habilidades para enfrentarem as exigências sociais, o mercado de trabalho. Na verdade, o que se pretende é interagir com esses alunos, pelo menos inicialmente, na sua própria linguagem, com os seus próprios valores, gostos e preferências, sem objetivar substitui-los por outros estranhos a eles, pois, com uma linguagem estranha, ninguém consegue interagir, nem produzir conhecimentos. Com uma linguagem estranha, não se consegue uma interlocução ativa e responsiva, uma contrapalavra, como uma faísca elétrica que só se produz quando há contato dos dois pólos opostos (Bakhtin, 1988, p. 132). Provavelmente se consiga impor, o que não possibilita nem uma dialogia, nem uma construção de percepções e de conhecimentos novos.

Um trabalho desfronteirado, que vem sendo proposto por vários autores, em vez de restringir o universo de leituras àquele preferido pelos mais diferentes leitores jovens, ao contrário, soma a esse universo o patrimônio literário e outras produções literárias por eles ainda não conhecidas.

Não é possível deixar de considerar, com a entrada das camadas populares para a escola, uma multiplicidade de objetos culturais e, portanto, de materiais de leitura, que adentram o espaço escolar como experiências desses alunos.

Nesse sentido, a História do Livro e da Leitura postula que se alarguem as possibilidades de conhecimento, em sentido oposto: podemos começar tentando conhecer e entender as práticas, os objetos e os modos de ler distintos daqueles presentes nos meios eruditos. Para isso, não precisamos nos esquivar de qualquer julgamento ou hierarquia, até porque os grupos culturais avaliam suas próprias produções e decidem que há algumas melhor realizadas que outras. O que parece inadequado, entretanto, é avaliar todas as composições segundo os critérios pertinentes à criação erudita. Essa postura nos levaria a perceber que não há livros bons ou ruins para todos, pois nem todos compartilham dos mesmos critérios de avaliação. Podemos começar a pensar que as leituras são diferentes e não piores ou methores (Abreu, 2000, p. 132).

Para se compreender melhor essa ausência de fronteiras, a proposta de Abreu prevê uma via de mão dupla, em que a literatura canônica e a considerada não-canônica possam circular, o 
que para alguns significará refletir sobre sua própria cultura e para outros, o conhecimento das variadas formas de criação poética ou ficcional (id. ib.).

Da mesma forma, considerando impossível compreender a literatura fora do contexto global da cultura, Bakhtin (1997, pp. 362/368) afirma que, numa dialogia entre culturas, formulamos a uma cultura alheia novas perguntas que ela mesma não se formulava e que a cultura alheia nos responde, revelando-nos seus aspectos novos, suas profundidades novas de sentido. Seria um comportamento curioso, uma compreensão ativa de tudo quanto é outro e alheio, nas suas potencialidades, nas suas riquezas. O autor acrescenta que o encontro dialógico de duas culturas não thes acarreta a fusão, a confusão; cada uma delas conserva sua própria unidade e sua totalidade aberta, mas se enriquecem mutuamente.

\section{Formação de Professores}

Enfim, como construir professores-mediadores, para traba1harem na escola a dimensão cultural da literatura? Que tipo de formação oferecer para que os professores possam se construir como mediadores de literatura e, mais amplamente, como mediadores culturais?

Nos nossos dias, os processos de formação de professores se complexificam mais. Redobra-se a necessidade de uma formação de professores de português ao mesmo tempo abrangente - cultural, ética, estética, informática -, e específica - lingüística, textual, discursiva e literária - a fim de contribuir competentemente na realização dos projetos interdisciplinares. Tal formação poderá contribuir também para a realização de um trabalho efetivo com a recepção e produção crítica de textos de usos públicos, principalmente os textos de imprensa e os textos eletrônicos, num momento em que já se fala em ciberespaço de produção e recepção de textos e de jogos, bem como nas possibilidades da literatura hipertextual, que permite um alto grau de intervenção por parte do leitor (Brasil, 2000). A este cabe, como condição de leitura, a possibilidade de, buscando atender os seus próprios objetivos, puxar os fios, destecer nós, ao mesmo tempo em que amarra outros fios, tece outros nós (Walty et al, 2000).

O que se pleiteia nessas circunstâncias é uma necessária integração, através de núcleos de formação docente, entre os 
conhecimentos das mais diversas áreas, para que seja propiciada uma formação que possibilite aos professores trabalharem e explorarem adequadamente os mais variados tipos de discurso, entre eles o literário, em suas diferentes manifestações culturais.

Em se tratando das potencialidades dessas manifestações culturais relacionadas à formação cultural de professores, segundo Magda Soares (2004, p. 32), nós, os educadores comprometidos com a formação de leitores, devemos assumir essa formação não apenas como desenvolvimento de habilidades leitoras e de atitudes positivas em relação à leitura, mas também, talvez sobretudo, como possibilidade de democratização do ser humano.

\begin{abstract}
This text intends to raise some reflections about school mediation in the schooling processes of literary reading. At first it comments on the reading production of three texts of different kinds, made by teachers during the graduate process, revealing a plurality of reading possibilities in the relationship among authorship/texts/readers. It also establishes a differentiation between teaching and mediation, mainly in the field of cultural demonstrations, in literature considered as artistic production. It points to the need of designing projects towards the teachers' cultural education aiming at readers' formation and reading democratization.
\end{abstract}

KEY WORDS: schooling process, mediation, literary reading, cultural education

\title{
Referências
}

ABREU, Márcia. 2000. As variadas formas de ler. In: PAIVA, Aparecida, EVANGELISTA, Aracy, PAUlinO, Graça, VERSIANI, Zélia. No fim do século: a diversidade: O jogo do livro infantil e juvenil. Belo Horizonte: Autêntica, p. 121-34.

BAKHTIN, Mikhail. 1988. Marxismo e filosofia da linguagem. São Paulo: Hucitec.

1997. Os gêneros do discurso / [Os estudos literários hoje]. Estética da criacão verbal. Tradução Maria Ermantina G. Pereira. São Paulo: Martins Fontes, p. 277-87/359-68.

BARBIERI, Marcius. O cego estrangeiro.

BARROS, Manoel de. 2000. O livro das ignorãcas. $7^{\mathrm{a}}$ ed. Rio de Janeiro: Record. 
Salamandra.

2001. O fazedor de amanhecer. Il. Ziraldo. Rio de Janeiro:

BOURdieU, Pierre. 1983. Gostos de classe e estilos de vida. Pierre Bourdieu: Sociologia. (organizador [da coletânea] Renato Ortiz). Trad. Paula Montero e Alícia Auzmendi. São Paulo: Ática.

BRASIL, André. 2000. Texto em mutação. In: PAIVA, Aparecida, EVANGELISTA, Aracy, PAULINO, Graça, VERSIANI, Zélia. No fim do século: a diversidade - o jogo do livro infantil e juvenil. Belo Horizonte: Autêntica, p. 89-96.

CAILLET, Élisabeth. 1995. À l'Approche du Musée, la Médiation Culturelle. Paris : PUL.

ECO, Umberto. 1986. O Leitor-Modelo. Lector in Fabula. São Paulo: Perspectiva, p. 35-49.

EVANGELISTA, Aracy Alves Martins. Escolarização da literatura entre ensinamento e mediação cultural: formação e atuação de quatro professoras. Faculdade de Educação/UFMG, 2000. (Tese de doutorado).

GUMBRECHT, Hans Ultich. 1998. As Conseqüências da Estética da Recepção: um Início Postergado (Capítulo 1). ROCHA, João Cezar de Castro (org.). Corpo e forma: ensaios para uma crítica não-hermenêutica. Trad. Heloisa Toller Gomes. Rio de Janeiro: EdUERJ, p. 23- 46.

LAJOLO, Marisa. 1995. Natureza interdisciplinar da leitura e suas implicações na metodologia do ensino. In: ABREU, Márcia (org.). Leituras no Brasil: antologia comemorativa pelo $10^{\circ}$ COLE. Campinas, SP: Mercado de letras, p. 113-28.

LOPEZ, Luiz Roberto. 1996. Música erudita: um privilégio para iniciados? Presenca Pedagógica, v. 2, n 11, set./out., p. 58-61.

OLIVEIRA, Letícia Mendes de. 2001. Leitura e Interpretação sobre a questão dos catadores de papel e a exclusão social. Faculdade de Educação, UFMG. (Projeto de Estágio - Prática de Ensino de Português).

SOARES, Magda Becker. 1988. As condições sociais da leitura: uma reflexão em contraponto. In.: ZILBERMAN, Regina \& SILVA, Ezequiel Theodoro da. (Orgs.). Leitura: Perspectivas Interdisciplinares. São Paulo: Ática, p. 18-29.

Leitura e democracia cultural. 2004. In: PAIVA, Aparecida; MARTINS, Aracy; PAULINO, Graça; VERSIANI, Zélia. Democratizando a Leitura: pesquisas e práticas. Belo Horizonte: Ceale; Autêntica, p.17-32. Coleção Literatura e Educação.

THOMAS, Gayle. Um conto Sufi. Derek Lamb: Canadá.

WALTY, Ivete, FONSECA, Maria Nazareth Soares, CURY, Maria Zilda Ferreira. 2000. Palavra e imagem: leituras cruzadas. Belo Horizonte: Autêntica. 